\title{
"QQué cuadro tan triste por cierto, presentaría la nación mexicana, cuando todas las sectas y todas las religiones, por monstruosas que sean, se disputasen en ella el campo!" Prensa y libertad religiosa en la ciudad de México (1833-1857)
}

Ínigo Fernández Fernández

\begin{abstract}
Resumen: Uno de los aspectos más importantes en el proceso de secularización que atravesó México en el siglo XIX fue, sin lugar a dudas, el de la lucha por el establecimiento de la libertad de cultos. En el presente texto aspiramos tanto a dar una visión panorámica de los principales argumentos que la prensa liberal dio a favor de ella y de aquellos esgrimidos por la conservadora en su contra, como a presentar las discusiones que en la materia sustentaron ambos tipos de publicaciones. Para tal fin consultamos la prensa capitalina a partir de 1833, cuando se aplicó por vez primera en México una legislación de orden liberal, y hasta 1857, año en el que se promulgó la primera constitución que antepuso los derechos de los ciudadanos a la organización del Estado.
\end{abstract}

Palabras clave: Prensa, siglo XIX, libertad religiosa, ciudad de México, liberal, conservador

\section{A MANERA DE INTRODUCCIÓN.}

Con la consumación de la independencia, los pensadores y políticos mexicanos se dieron a la tarea de dar vida a la nueva nación. De esta forma, surgieron distintos proyectos que, ya fuera encarnados en el monarquismo y el republicanismo, el centralismo y el federalismo o el consevadurismo y el liberalismo, aspiraron a incidir directamente en la construcción del país.

El paso de los años demostró que la tarea sería compleja. Eran pocas las similitudes que compartían los distintos Méxicos que cada grupo político concebía y cada vez más las diferencias que imperaban entre ellos; diferencias que no sólo llevaron al descrédito mútuo, también a una lucha por el poder que se peleó más en el campo de batalla que en las tribunas y las urnas.

Está búsqueda por "dotar de ser" a México, como diría el historiador Edmundo O'Gorman (1986), llevó al conocido enfrentamienro que conservadores y liberales protagonizaron en el siglo XIX. En tanto que los primeros se hallaban estrechamente vinculados a la Iglesia católica, a los segundos les correspondió 
lo mismo ser oposición, en ocasiones, que gobierno en otras.

Si bien el conservadurismo y el liberalismo, como ideologías, no fueron gestados en México, su adopción no implicó su aplicación irreflexiva. Por el contrario, los grupos que abrevaron en ellas las ajustaron tanto a las circunstancias propias de la nación como a las necesidades políticas que cada uno de ellos poseía.

El conservadurismo nació en Europa a fines del siglo XVIII como una reacción contra la "amenaza" que representaban las ideas y logros alcanzados por la Revolución Francesa (Noriega, 1993: 45). En el caso mexicano, los elementos más representativos del conservadurismo se hicieron presentes a partir de la década de los años treinta del siglo XIX cuando, según lo dicho por Renée de la Torre y Juan Manuel Ramírez, dio inicio una apología de "la defensa de la libertad económica y la diversificación de las actividades productivas, el rechazo a las milicias cívicas y la defensa del ejército, el rechazo al régimen federal y la defensa del centralismo y del orden público, y, finalmente, la defensa de la Iglesia, sus bienes y privilegios" (2005: 52). En ese sentido, la religión católica se erige lo mismo en garante de la tradición que en pilar de una moral pública y nacional.

El liberalismo, por su parte, surgió en el país en la misma época y bajo el cobijo del "Partido del Progreso". Desde sus inicios se cracterizó por promover el reconocimiento y respeto de las libertades del ser humano y por concebir las leyes e instituciones como instrumentos para procurar el progreso: "las convicciones al respecto van desde el fetichismo de la ley y la institución, asignando a éstas facultades milagrosas, hasta los que siguiendo un idealismo práctico creen que, dentro de ciertos límites, el derecho público ejerce una acción transformadora de la realidad" (Reyes Heroles, 1957: x).

Una de las libertades que más defendió el liberalismo fue la religiosa dado que era considerada como uno de los factores que poseían mayor incidencia en el desarrollo espiritual y material del pueblo mexicano. Como es de suponer, la naturaleza propia de este prinicipio era contraria al postulado conservador de defender los privilegios del clero, de tal manera que se llegó a una situación en la que le defensa de los prinicipios propios y el ataque contra los ajenos se convirtió en el único camino a seguir para ambos grupos.

En el presente texto, daremos cuenta de las disputas que conservadores y liberales sostuvieron en torno al tema de la libertad de cultos en México. Para tal fin, consideramos que el estudio de los periódicos liberales y conservadores que circularon en la capital mexicana entre 1833 y 1857 son una fuente de información fundamental que nos permitirá documentar este proceso desde una perspectiva original por estar aún poco trabajada. Por el lado conservador, las publicaciones en cuestión son: La Antorcha (1833), La Cruz. Periódico exclusivamente religioso, establecido exprofeso para difundir doctrinas ortodoxas y vindicarlas de 
"iQué cuadro tan triste por cierto, presentaría la nación mexicana, cuando todas las sectas y todas las religiones, por monstruosas que sean, se disputasen en ella el campo!

los errores dominantes (1855-1855), El llustrador católico mexicano (1833), El Ómnibus (1851-1856), y La Voz de la Religión (1848-1851); en tanto que las liberales son: El Demócrata. Federación o muerte (1833-1834), El Indicador de la Federación Mejicana (1833-1834), EI Monitor Republicano y EI Siglo XIX (1841-1857).

Por último, resulta necesario señalar que nuestro marco temporal se sitúa entre el primer intento por establecer un gobierno liberal en México y la proclamación de la Constitución de 1857, documento en el que el poder civil procuró distanciarse de la Iglesia católica.

\section{LA LIBERTAD RELIGIOSA EN LA PRENSA LIBERAL.}

Debemos empezar por señalar que, en la materia, la prensa liberal, no así la conservadora, destacó dos tipos de libertades que aunque se asemejan, no son iguales: la de conciencia y la de cultos. En EI Siglo XIX del 31 de julio de 1856 se explicó que la primera se concebía como la esencia misma de los derechos del hombre por constituirse en aquella libertad de pensamiento que permitió a los mexicanos decidir seguir siendo católicos una vez consumada la independencia. El 5 de agosto de 1856, el diputado Francisco Zarco defendió en las páginas del mismo periódico que aquélla era el espacio donde podía incidir la acción del legislador y aseguró que "nada, pues, tiene que agradecer la causa de la civilización a los que aquí proclaman la libertad de conciencia y se detienen sin dar un paso adelante. ¿De que servirá un derecho que nadie podrá ejercer?".

El 30 de julio de 1856 se explicó en las páginas del antes citado Siglo XIX que la libertad de cultos, también conocida en la época como tolerancia religiosa, era entendida como el derecho que debían tener los habitantes del país para elegir y profesar libremente cualquier credo religioso y en un principio era consecuencia forzosa de la libertad de conciencia. Respecto a la tolerancia, y dados los ataques que el concepto sufrió por parte de los periódicos conservadores, y en particular los católicos, se recurrió a la definición que de ella había dado Voltaire en su Diccionario filosófico: "[...] el patrimonio de la humanidad. Todos estamos llenos de debilidades y de errores: perdonemos, pues, recíprocamente nuestras necedades, porque tal es la primera ley de la naturaleza'. Todo lo cual está comprendido en éstas sublimes palabras del Hijo de Dios: AMAOS LOS UNOS A LOS OTROS"."

1 Al consultar la obra en línea encontramos algunas diferencias con el texto citado pues la versión revisada dice: “¿Qué es la tolerancia? Es la panacea de la humanidad. Todos los hombres estamos llenos de debilidad y de errores, y debemos perdonarnos recíprocamente, que ésta es la primera ley de la Naturaleza". Cfr. Voltaire. Diccionario filosófico. Valencia, Sociedad Editorial 
El tema de la libertad de cultos estuvo presente en la hemerografía y la política desde la consumación de la independencia nacional. En 1833, año en el que inicia nuestro estudio, los diputados Escudero, Riveroll y Riva Palacio presentaron en el Congreso un proyecto que promovía la libertad plena en materia religiosa. La propuesta contó con el apoyo de EI Demócrata, publicación que el 31 de agosto de 1833 aseguró que "adore enhorabuena cada uno a Dios según su conciencia, y viva enhorabuena en aquellas prácticas o ejercicios con que mejor le parezca que puede agradar a la divinidad; pero a nadie se le obligue a que adopte por fuerza tal o tal modo de vivir, o a que lo conserve porque una vez que lo adoptó cuando tal vez no se sentía con fuerzas para los actos heroicos de virtud que pudo ejercer en otro tiempo".

El escrito, además, defendía la idea de que si la Constitución de 1824 apoyaba la libertad de pensamiento en México, la autoridad civil no podía promover la profesión forzosa de cualquier culto. En realidad se trataba de una interpretación muy particular de la carta magna pues mientras que en su artículo $4^{\circ}$ asentaba que que la religión católica era la única tolerada en el país; el inciso $4^{\circ}$ del artículo 161 establecía que lo estados debían garantizar a sus ciudadanos la libertad para escribir, imprimir y publicar sus ideas políticas sin necesidad de recurrir a la censura previa. En realidad, la argumentación presentada carecía de validez pues la libertad de pensamiento avalada por las leyes comprendía al ámbito político mas no al religioso.

El mismo diario publicó otro artículo el 2 de noviembre de 1833 en el que se afirmaba que en aquellas naciones que contaban con tal derecho, su moral había mejorado; su población aumentado; su agricultura, industria y expresiones artísticas progresado, y el saber perfeccionado en detrimento de la ignorancia y la superstición, ambos males que, aunque no se mencionara explícitamente, aquejaban al país. Vale la pena señalar que dicha argumentación aparecería constantemente en las publicaciones liberales y se mostraría como una manifestación más de la civilización.

Por su parte, el 11 de diciembre de 1833 El Indicador de la Federación Mexicana abordó el asunto con dos textos que, pese a ser anónimos, poseen la impronta del doctor José María Luis Mora. El primero criticó que las autoridades políticas mexicanas recurrieran a la fuerza para hacer cumplir los deberes religiosos de la población y sentenció que gracias a ello:

Prometeo, S. F., <http://www.e-torredebabel.com/Biblioteca/Voltaire/tolerancia-DiccionarioFilosofico.htm> (30/mayo/2015). 
"iQué cuadro tan triste por cierto, presentaría la nación mexicana, cuando todas las sectas y todas las religiones, por monstruosas que sean, se disputasen en ella el campo!

Prensa y libertad religiosa en la ciudad de México (1833-1857)

mandan creer o no creer alguna cosa, las que castigan como crímenes los errores, las que imponen suplicios a los que no creen en un dogma, o lo que es lo mismo, los que tienen por falso o por dudoso lo que otros juzgan verdadero e incontrovertible [...]; las que mantienen por fuerza en un monasterio a los que no tienen ya vocación para evitarlo; las que imponen las dotes al que no se confiesa ni comulga, multas [...] al que no paga el diezmo; las que autorizan a los gobiernos para elegir a los que han de ejercer el sacerdocio; las que dan intervención al sacerdocio en los negocios públicos [...].

La virulencia de estos comentarios contrasta con el lenguaje considerado, conciliador incluso, del segundo artículo, aparecido el $1^{\circ}$ de enero de 1834 , y en el que se apelaba a principios como el de la razón y la justicia para defender la tolerancia de cultos. Es más, se llegó hasta el extremo de referirse a la piedad para tal fin en términos de confort, compasión, dulzura y ternura. Llama la atención que se recurriera a un término estrechamente vinculado a lo religioso para defender la libertad de cultos, recurso que será habitual en la prensa liberal, lo mismo que el uso continuo de referencias del Evangelio y, en particular, de la vida de Jesucristo como muestra de caridad, dulzura y tolerancia.

El tema de la libertad de cultos adquirió especial relevancia a finales de la década de los años cuarenta una vez que concluyó la guerra contra Estados Unidos. Y es que para los liberales, una de las causas que dio origen a este conflicto había sido el escaso poblamiento del norte del país; de ahí que propusieran como medida preventiva el establecimiento de colonos extranjeros en las regiones más septentrionales de la República. Sin embargo, se decía que el proyecto no podría funcionar mientras que la religión católica siguiera siendo la única tolerada en México.

EI Siglo XIX destacó lo anterior pocos meses después de haberse firmado los Tratados de Guadalupe Hidalgo el 2 de febrero de 1848, al asegurar en un artículo aparecido el 29 de julio de ese mismo año que "el más conveniente [de los medios para demostrar que la tolerancia de cultos es oportuna], a nuestro entender, es el de la necesidad imperiosa que tenemos de ofrecer este poderoso aliciente a los extranjeros, que no vienen a establecerse entre nosotros por no abandonar el culto de sus padres [...]". De igual forma, sostuvo que se trataba de una auténtica reforma social que permitiría a los mexicanos sacar provecho de las desgracias pasadas (entiéndase el conflicto referido) e introducir las mejoras necesarias para la nación.

Un año más tarde, El Monitor Republicano se sumó a este llamado y el 2 de agosto apeló a los legisladores para que hicieran lo necesario en aras de favorecer la emigración extranjera "para que hombres útiles sean los que emigren, es indispensable que se les den ventajas reales, positivas y bien aseguradas [entre ellas la libertad de cultos]: de otro modo no se puede obtener una población útil. Nuestros legisladores deben proporcionar tales ventajas: de ellos depen- 
de el que tengamos buena población. Nosotros levantamos nuestra voz para llamar su atención sobre un objeto de interés tan vital"; postura que seguiría manteniendo con los años.

En los años cincuenta, mientras que EI Siglo XIX apoyó la lucha por la tolerancia de cultos publicando los debates que, sobre el tema, estaban teniendo lugar en el parlamento español, El Monitor Republicano retomó de nueva cuenta este razonamiento al vincular el cristianismo con la libertad "porque es la religión [cristiana] de los que aman la libertad, y están prontos a dar la sangre de sus venas por sus hermanos; porque principal fundamento de ella es este precepto, en el que se resuma toda la moral: ama a tu hermano como a ti mismo, y lo que no quieras para ti, no lo quieras para él", según el artículo del 18 de abril de 1851. De hecho, la publicación solía utilizar constantemente la palabra "hermanos" para defender su postura puesto que la consideraban como una manifestación del espíritu fraternal enarbolado por la llustración.

El 22 de abril de 1856, y a la luz de las discusiones que tenían lugar en la cámara de diputados en torno a si la nueva constitución contemplaría o no la libertad de cultos, el liberal José J. González publicó un artículo en El Monitor Republicano donde establecía que dado que los mexicanos estaban convencidos de que el catolicismo era la verdadera y única religión, la tolerancia de credos en nada mermaría su fe y su devoción y, en cambio, se permitiría que muchos "infieles" europeos disfrutaran de la hospitalidad mexicana. La primera parte de la argumentación contenía una premisa que utilizaba con argucia los argumentos de la Iglesia para salirse con la suya, de tal suerte que la libertad de cultos se presentaba como el medio para que la Iglesia pudiera demostrar precisamente aquello que tanto temía perder con ella: su superioridad ante los otros credos. Algo similar sucedería meses después, el 31 de julio de ese mismo año, cuando apareció un texto anónimo que concluía con la frase "los más católicos, los más religiosos son los que, por el hecho mismo de comprender los preceptos evangélicos, defienden la tolerancia".

Contrario a lo anterior, los más devotos fueron los que mayor resistencia ofrecieron ante la propuesta, constituyéndose así en una oposición por demás incómoda que fue calificada por los liberales de "fanática" en materias religiosa y política.

III. LA LIBERTAD DE CULTOS EN LA PRENSA CONSERVADORA.

Desde su primer número, aparecido el primero de abril de 1833, La Antorcha defendió al catolicismo como religión única del país y, para tal fin tomó como referente al gobierno federal al hacer pública una circular que el Ministro de 
"iQué cuadro tan triste por cierto, presentaría la nación mexicana, cuando todas las

Justicia, Manuel Ramos Arizpe, envió a los prelados diocesanos y regulares en la que aseguraba que, dados los consuelos que la religión prodigaba al país, el gobierno se obligaba a mantener con la debida decencia al culto y sus ministros.

Cinco días más tarde, el periódico dio los nombres de algunos de aquellos enemigos del orden constitucional a los que se refería el presidente. Se trataba de tres diputados -Escudero, Riveroll y Riva Palacio- quienes habían presentado un proyecto de ley en la Cámara de Diputados para que en imperase en el país la libertad absoluta en materia de religión. En cuanto el proyecto de ley pasó a comisiones, los editores de La Antorcha iniciaron una campaña en su contra. En el número del 17 de abril de 1833 afirmaron que la reforma al artículo $3^{\circ}$ había dejado de ser un temor infundado y que eran cuatro las clases de personas que secundaban tal meta

[...] los extranjeros, parte en obsequio de su culto particular, parte para secundar las miras de sus naciones, haciendo la guerra de ideas y de opinión al sucesor de S. Pedro; algunos mexicanos aduladores de éstos y para quienes nada hay bueno sino lo extranjero, sin exceptuar la religión; los libertinos que tratan de satisfacer descaradamente sus pasiones sin la nota de irreligiosos: los enemigos de nuestra independencia que [...] tienen el mayor empeño en mantenernos en una revolución perpetua, para que fastidiados de ella nos entreguemos en un acceso de despecho a las manos de un tirano.

En virtud del contexto histórico mexicano, suponemos que entre los primeros se hacía referencia a Joel Roberts Poinsett —quien fue el primer representante del gobierno estadounidense en México entre 1825 y 1829. Destacó por sus constantes intervenciones en la política interna mexicana, por promover el acercamiento de México con Estados Unidos y por fundar la primera logia federalista en el país - ${ }^{2}$, entre los segundos a los liberales, entre los terceros a los miembros del Partido del Progreso y entre los últimos a los diputados citados.

De igual manera, el diario puso sus páginas al servicio de aquellos lectores que quisieran compartir con otros sus opiniones. Entre todos, destaca un remitido firmado por unos ciudadanos y que apareció el 17 de abril de 1833. En él se indicaba que la propuesta "[...] abre un paso franco no sólo á un ciudadano de mala cabeza para que escriba cuanto se le antoje contra la Religión, sino también al judío, al mahometano, al protestante, etc, para que dogmaticen a su gusto abonando sus creencias particulares"; mientras que el 8 de mayo alguien que firmaba como $\mathrm{N}$ se cuestionaba "¿de qué serviría que en la Constitución política de una Nación se diga que la Religión católica es la única verdadera, y

2 Biographical Directory of the United States Congress,

<http://bioguide.congress.gov/scripts/biodisplay.pl?index=P000404>, (20/abril/2014) y Joel Roberts Poinsett, <http://www.sumtersc.gov/AboutSumter/History_Poinsett.aspx>, (20/ abril /2014). 
la única que se permite profesar; si atolondrados é imprudentes periodistas se atreven á hacer burla y rechifla de prácticas y creencias que el pueblo tiene por muy piadosas, y por inherentes a la sustancia misma de la Religión?".

Sabemos que el proyecto de ley finalmente no fue aprobado por el Congreso, si bien el tema continuó estando presente en el debate público. En la documentación hemerográfica investigada, encontramos una nueva referencia el 9 diciembre de 1846 cuando El Ilustrador católico publicó una reseña del acto de apertura de las sesiones del congreso general mexicano. Desconocemos de quién eran las palabras citadas, pero si sabemos que, en su calidad de orador hablaba a nombre de la totalidad de la legislatura:

Al hablar de religión, nosotros no podemos esperar otra que la católica, apostólica y romana; esa religión de nuestros padres, que civilizó nuestro país; que han respetado hasta aquí todos nuestros legisladores, y á la que ninguna nación puede renunciar sin traicionarse á sí misma y desconocer sus verdaderos intereses; esa religión que aman los pueblos todos de nuestra república, y que reconocen como su primer deber y su más imperiosa necesidad; esa religión única verdadera, con exclusión de todas las demás, y que, por una grande fortuna nuestra, es la sola que profesa la gran familia mexicana [...].

Pese a tratarse de una artículo aislado, creemos que es de un especial interés pues detrás de la exaltación de la religión católica se encontraba un llamado de atención para los mexicanos quienes, en su guerra contra Estados Unidos, no sólo corrían el riesgo de perder su independencia o su territorio, sino sino que hasta podían ser obligados a apostatar para abrazar el protestantismo.

En 1848, una vez terminado el conflicto, la prensa liberal tachó de intolerantes a los políticos conservadores y miembros del clero por su negativa a establecer la libertad religiosa en el país. La Voz de la Religión no estaba de acuerdo con tal calificativo, por lo que el 26 de agosto publicó una serie de contribuciones para debatirlo. Así, J.R.D.S.M explicó que "en la discusión de esta materia, es interesantísimo no perder de vista que la palabra intolerancia es equívoca. Si se toma en el sentido de no sobrellevar que otro en sí profese otra religión, odiar y perseguir con celo, indagar los actos internos y llevar a una hoguera [...]; pero ¿hay esta clase de intolerancia en nuestros días, y ha existido hace muchos años? [...]"; mientras que en otro escrito, una carta firmada por J.E.O., se dilucidaba que la tolerancia de cultos no significaba anuencia de ideas que no se externaban y que sólo ejercieran una influencia interna en el ser humano; tampoco era un acto interno con el que se adorase a Dios.

En otra contribución anónima del 26 de agosto de 1848, se diferenciaba entre la tolerancia verdadera y la filosófica pues se aseveraba que la segunda, hija de la Revolución Francesa, se había distinguido por su carácter imposicionisa e intolerante en tanto que, y a manera de contraste, "los verdaderos amigos de 
"iQué cuadro tan triste por cierto, presentaría la nación mexicana, cuando todas las

la religión son menos severos; piden, proclamando la verdad, indulgencia para el error".

Dicha diferenciación puso de manifiesto el interés de los periódicos conservadores por definir el concepto de "tolerancia", eje fundamental en la propuesta liberal. Todas las explicaciones encontradas fueron notoriamente inspiradas por las palabras de Don José María Díez de Sollano, teólogo y defensor del escolasticismo en México, quien en un artículo aparecido en el mismo periódico el 30 de agosto de 1848 la describió como

[...] el sufrimiento de una cosa que se conceptúa mala, que se cree conveniente dejarla sin castigo. Así se tolera cierta clase de escándalos: se toleran las mujeres públicas; se toleran atropellos y abusos; de tal manera que la tolerancia anda siempre acomunada de la idea de maldad. Tolerar lo bueno, tolerar la virtud, serían expresiones monstruosas. Cuando la tolerancia es en el orden de las ideas, supone también un mal entendimiento, el error. Nadie dirá jamás que ella tolera la verdad.

Para apoyar la causa, La Voz de la Religión también editó en sus páginas un artículo publicado el 23 de agosto del mismo año, titulado "Carta de Teophilo a Philopatro" que, en realidad, era un ensayo contra la libertad de cultos en el que se destacaba que tratándose la religión de un medio de disciplina y orden, la tolerancia civil se constituía en un mal que generaba la anarquía y la desunión entre los mexicanos; además, el hecho de que el catolicismo fuera el único credo tolerado no debía impedir que los extranjeros se asentaran en el país si eran protegidos y tratados con justicia. Su autor se mostraba seguro de que ningún legislador se atrevería a alterar la fe y las prácticas devotas en el país y que, de suceder lo contrario "lo que Dios no ha de permitir, en la historia de su Iglesia Santa, hallaremos un ejemplo glorioso que imitar", en una clara alusión a los mártires.

Hubo otros artículos, en cambio, en los que se establecía que antes de hablar de la libertad de cultos o de promover la colonización en el país, primero era necesario solucionar los problemas que lo aquejaban, tal como lo decía el escrito del 9 de septiembre titulado "La religión católica es firme apoyo de la república, y la mejor garantía de los derechos del hombre y del ciudadano en los países libres", y en el que su autor afirmaba que la abundancia, la estabilidad política, la moralidad y la paz eran argumentos mucho más poderosos que la libertad de credos para atraer a colonos provenientes de otras tierras. Esta postura encarnaba una argumentación conciliadora que sin adentrarse en el debate, ni tomar aparentemente postura en él, proponía como condición necesaria la solución de lo que al entender del autor eran los problemas fundamentales de México.

En los dos últimos meses de 1848 y los primeros de 1849 no apareció 
ninguna otra observación sobre el asunto por motivos que nos son desconocidos. No fue sino hasta el 3 de marzo de 1849 cuando resurgió el tema, pero sólo en tres artículos de los que los dos primeros son dignos de destacar por ser una protesta que el vicario capitular y el cabildo metropolitano de la ciudad de México hacían al gobierno federal y en donde certificaban que la religión única y verdadera era la católica y que, en consecuencia, ninguna otra debía ser permitida pues si otras eran toleradas "[...] millares de hombres de todas las religiones inundarían el país y serían precisamente los enemigos del catolicismo, supuesto que la tolerancia los llamaba; y esos hombres, diseminados por todas partes, influirían y dirigirían la educación política y religiosa de la niñez y de la juventud [...]".

En la década de los años cincuenta la historia tomó otro rumbo. A partir de 1853 el gobierno apoyó al culto católico de dos maneras. En un inicio, promulgó una ley de imprenta en cuyo artículo 23 , inciso l, definía como subversivos los impresos contrarios a la religión católica, según El Ómnibus de 28 de abril de ese año y, posteriormente, emitió un decreto por el que nombraba como consejeros honorarios de Estado al arzobispo de la ciudad de México y a los obispos del resto del país. Estas medidas no pasaron desapercibidas por el Papa Pío IX, quien en una carta escrita al presidente y publicada en el mismo periódico el 9 de septiembre de 1853 le manifestaba que "no ha sido poco el placer que nos ha causado esta disposición de tu ánimo, pues conociendo bien el estado que guardaba la ilustre nación mexicana, enviamos ahí nuestro delegado y de esta sede apostólica, con la intención y objeto de que dirigiese todos sus trabajos y diligencias al fomento de las cosas de nuestra santísima religión, en la cual estriba la tranquilidad, la felicidad y el orden público de los pueblos".

Con el triunfo de la revolución liberal de Ayutla en 1855 el nuevo gobierno se mostró interesado en revisar la cuestión de la libertad de cultos al tiempo que la prensa conservadora se lanzó de nuevo a la defensa del carácter único del catolicismo. El arzobispo de la ciudad de México, Lázaro de la Garza, editó un folleto que contenía varias pastorales, entre ellas una sobre la tolerancia religiosa que en su calidad de obispo de Sonora, había dirigido a su feligresía en 1848, misma que autorizó a El Ómnibus para reproducir en sus páginas el 27 de octubre de 1855. En ella, además de cuestionar la pluralidad religiosa y de evidenciar los males que ésta traería, y que en realidad no variaban significativamente de los argumentos ya expuestos, refutaba el carácter intolerante que los detractores del catolicismo le atribuían al afirmar que tal intolerancia era solamente con respecto a la creencia y doctrina y que fuera de este punto, el culto católico era el más tolerante.

Entre 1856 y 1857 La Cruz y El Ómnibus fueron los periódicos en los que el catolicismo se apoyó en su lucha contra la libertad y tolerancia de cultos. En el 
"¡Qué cuadro tan triste por cierto, presentaría la nación mexicana, cuando todas las

primer periódico, José Joaquín Pesado publicó una serie de artículos al respecto en los que vinculó el concepto de libertad religiosa con el filosofismo del siglo XVIII. El 10 de julio de 1856 se refirió al tema afirmando que "es muy común en muchos de los sectarios fanáticos de la libertad religiosa, de aquellos que proclaman incesantemente la fraternidad y la filantropía, el perseguir encarnizadamente al catolicismo [...]. Así como la verdad que siempre es consecuente consigo misma, así el error camina de unas contradicciones a otras hasta perderse en la duda universal". Llama la atención la alusión a la llustración francesa a través del uso de términos como "fraternidad" y "filantropía" que, en el contexto en el que eran citados, parecerían ser antagónicos al catolicismo.

Al mismo tiempo, el 18 de abril de 1856 El Óminibus reprodujo un artículo de Juan Bautista Morales -inicialmente publicado en un periódico llamado La Sociedad-, quien se había manifestado desde 1835 contrario a la libertad de credos. Sus comentarios fueron producto más de la reflexión que de la intransigencia pues consideraba que quienes defendían la libertad de credos tomaban como ejemplos a naciones en las que coexistían varios cultos, lo que en cierta medida representaba un proceder errado en virtud de que dicha situación era inexistente en México.

En julio de 1856 la cámara de diputados elaboró un proyecto de constitución liberal, lo que ocasionó un gran revuelo entre laicos y eclesiásticos porque en su artículo 15 establecía que "no se expedirá en la República ninguna ley, ni orden de autoridad que prohíba o impida el ejercicio de ningún culto religioso, pero habiendo sido la religión exclusiva del pueblo mexicano la católica, apostólica romana, el Congreso de la Unión cuidará, por medio de layes justas y prudentes, de protegerla en cuanto no se perjudiquen los intereses del pueblo". ${ }^{3}$

El primero en cuestionar el proyecto fue José Joaquín Pesado, quien realizó una serie de observaciones para El Ómnibus en las que el 10 de julio de 1856 abundó en el significado del término "tolerancia", tal vez como ningún otro laico lo hizo con anterioridad, y lo vinculó con el de "libertad" en un ejercicio que, probablemente, haya resultado de sumo interés para el público lector:

[...] la tolerancia dogmática consiste en afirmar que todas las religiones son indiferentes para alcanzar la salud eterna, y que en cualquiera de ellas, que el hombre viva, puede salvarse. [...]. ¿Si todas las religiones son igualmente buenas, a qué fin hizo Dios manifiesta su voluntad a los hombres? ¿Para qué ha conminado con suplicios eternos a los que se resistan a sus mandamientos? [...]. La libertad de cultos equivale a tanto como abrir la puerta a todos los errores, a todas las abominaciones que ha habido y hay en el mundo, a todos los extravíos

3 Constitución de 1857, <www.bibliojuridica.org/libros/1/328/9.pdf>, (30/mayo/2015). 
del espíritu humano, al desenfreno de todas las pasiones y a la perpetuación de todos los crímenes con pretexto de religión. Libertad absoluta de cultos, equivale a restituir la idolatría, si se quiere, con las turbulentas fiestas de Baco, y los impuros misterios de Venus [...].

De nueva cuenta, El Ómnibus abrió sus puertas a las contribuciones de los lectores para que manifestaran su parecer contra tal disposición. Para dar más impacto a los reclamos, y no tanto para parecer como una publicación de vanguardia, en los números del 17 y del 22 de julio de 1856 se publicaron cartas escritas por mujeres de toda la República Mexicana manifestándose contra la libertad de cultos, cuyo valor no radica en lo que aportaban al debate, pues repetían los argumentos esgrimidos tanto por los jerarcas católicos como por los varones laicos contra esta libertad, sino en que permiten la participación de las mujeres que, pese a provenir de las mejores familias del país, constituían un grupo cuya participación en la prensa y, en la consecuente formación de la opinión pública, era casi nula.

A final de cuentas, el artículo 15 del proyecto de constitución se modificó, de tal manera que cuando fue promulgada, el 5 de febrero de 1857, la libertad de cultos no estaba comprendida. Sin embargo, ello tampoco representó un triunfo para la Iglesia pues el artículo 123, el único que versaba sobre la religión, establecía que "corresponde exclusivamente a los poderes federales ejercer, en materia de culto religioso y disciplina externa, la intervención que designen las leyes", según se publicó en La Cruz el 19 de marzo de ese año. Es decir, los liberales cedieron en sus pretensiones pero, a cambio, se cobraron un alto precio al suprimir de la carta magna el concepto del catolicismo como religión de Estado.

El clero y los feligreses mostraron su descontento contra la medida, pero fue poco lo que lograron hacer pues ya estaban sentadas las bases para que meses después estallara una guerra civil que duraría tres años y que marcaría el triunfo del liberalismo en materia económica, política y hasta religiosa.

\section{CONCLUSIONES.}

El estudio de los procesos de secularización en México durante el siglo XIX demanda un cambio de paradigmas que deje a un lado tanto la visión unitaria y monolítica del conservadurismo y del liberalismo como los binomios -hoy en día caducos- de "liberal/ateo" y "conservador/católico". En el caso de la libertad de cultos, el presente análisis ha puesto en evidencia la existencia de dos corrientes liberales claramente diferenciadas. La primera, moderada y tolerante, defendía los vínculos existentes entre el catolicismo y la política; la segunda, radical y anticlerical, proponía la separación entre los poderes civil y religioso; 
"¿Qué cuadro tan triste por cierto, presentaría la nación mexicana, cuando todas las sectas y todas las religiones, por monstruosas que sean, se disputasen en ella el campo!

y pese a ello, ninguna de las dos planteaba la supresión de la Iglesia y de la religión.

La prensa conservadora, por contra, se mostró reacia a aceptar cualquier ajuste que modificara el proyecto de nación católica heredado de la época virreinal. No obstante ello, la consulta de fuentes como la correspondencia, los sermones y los libros escritos por algunos jerarcas eclesiásticos mexicanos -como Clemente de Jesús Munguía o Lázaro de la Garza y Ballesteros- son testimonio de un catolicismo moderadamente liberal que reconocía que el vínculo entre la Iglesia y el estado en México debía actualizarse.

La revisión de los periódicos de la época nos permite situarnos ante un tema que si bien representó uno de los puntos más delicados de la agenda de liberales y conservadores, no fue campo fecundo para un auténtico debate. Unos y otros recurrieron a las publicaciones periódicas para mostrar las bondades de los argumentos propios y desmantelar los defendidos por "el otro", pero rara vez para debatir entre sí.

Al respecto, en el presente estudio coincidimos con lo expresado por Brian Connaughton, quien ha caracterizado a la década de los años cincuenta como un tiempo de crisis, de confrontación y de preponderancia de una opinión pública cada vez más polarizada.

Es innegable que la prensa debe ser considerada como una fuente primordial para el estudio del pasado por tratarse de un espejo privilegiado que, en este caso, nos permite observar y estudiar el proceso de secularización en México a través de uno de los aspectos que revistió mayor importancia en el siglo XIX y que no quedaría resuelto sino hasta 1860 con la promulgación de la Ley sobre libertad de cultos. 
BIBLIOGRAFÍA

IMPRESAS:

\section{A) BIBLIOGRÁFICAS:}

Constitución DE 1824. (1828). México, Imprenta de Galván, t. 1, p. 2. [edición facsímil Colección de Constituciones de los Estados Unidos Mexicanos. Régimen constitucional de 1824, editado por Mariano Galván Rivera. México, Miguel Ángel Porrúa, 1988].

García Ugarte, Martha Eugenia. (2005). "Tradición y Modernidad (1810-1840)”, en De la Torre, Renée, María Eugenia García y Juan Manuel Ramírez (coomp.). Los rostros del conservadurismo mexicano, México, Centro de Investigaciones y Estudios Superiores en Antropología Social, pp. 35-70.

NoRIEGA, Alfonso. (1993). El pensamiento conservador y el conservadurismo mexicano, México, UNAM, Instituto de Investigaciones Jurídicas, vol. 1.

O'Gorman, Edumndo. (1986). La supervivencia política novohispana, México, Universidad Iberoamericana.

Reyes Heroles, Jesús. (1957). El liberalismo mexicano. México, UNAM, 1957, t. 2.

B) HeMERográficAs:

El Demócrata. Federación o muerte (1833-1834).

El llustrador católico mexicano (1833).

El Indicador de la Federación Mejicana (1833-1834).

EI Monitor Republicano y EI Siglo XIX (1841-1857).

El Ómnibus (1851-1856).

La Antorcha (1833).

La Cruz. Periódico exclusivamente religioso, establecido exprofeso para difundir doctrinas ortodoxas y vindicarlas de los errores dominantes (1855-1858).

La Voz de la Religión (1848-1851).

DIGITALES:

Biographical Directory of the United States Congress, <http://bioguide.congress. gov/scripts/biodisplay.pl?index=P000404>, (20/abril/2014).

Constitución de 1824.

http://www.cervantesvirtual.com/servlet/SirveObras/79117288329793495200080/ 
"¿Qué cuadro tan triste por cierto, presentaría la nación mexicana, cuando todas las sectas y todas las religiones, por monstruosas que sean, se disputasen en ella el campo!

Prensa y libertad religiosa en la ciudad de México (1833-1857) p0000001.htm\#I_1_(31/mayo/2015).

Constitución de 1857, <www.bibliojuridica.org/libros/1/328/9.pdf>, (30/mayo/2015). Joel Roberts Poinsett, <http://www.sumtersc.gov/AboutSumter/History_Poinsett.as$p x>,(20 / a b r i l / 2014)$.

Voltaire. Diccionario filosófico,

http://www.e-torredebabel.com/Biblioteca/Voltaire/tolerancia-Diccionario-Filosofico. htm, (30/mayo/2015). 
